\title{
Multiple trait and random regression models using linear splines for genetic evaluation of multiple breed populations
}

\author{
V. M. P. Ribeiro, ${ }^{1}$ F. S. S. Raidan, ${ }^{2}$ A. R. Barbosa, ${ }^{1}$ M. V. G. B. Silva, ${ }^{3}$ F. F. Cardoso,${ }^{4}$ and F. L. B. Toral ${ }^{1 *}$ \\ ${ }_{1}^{1}$ Departamento de Zootecnia, Escola de Veterinária, Universidade Federal de Minas Gerais, Belo Horizonte, MG 31270-901, Brazil \\ ${ }^{2}$ CSIRO Agriculture \& Food, Brisbane, QLD 4067, Australia \\ ${ }^{3}$ Embrapa Gado de Leite, Juiz de Fora, MG, 36038-330, Brazil \\ ${ }^{4}$ Embrapa Pecuária Sul, Bagé, RS, 96401-970, Brazil
}

\section{ABSTRACT}

This study aimed to verify if random regression models using linear splines (RRMLS) are suitable for identifying genetic parameters in multiple-breed populations and also to investigate whether an interaction exists between the breeding value (BV) of sires and their progeny breed group. Ten populations were simulated by crossing 2 breeds with distinct genetic variance and nonzero segregation variance. To obtain the genetic parameters, 2 models were used: a multiple-trait model (MULT), in which the trait was considered distinct when evaluated in each group $\left(1 / 2 \mathrm{P}_{1}+1 / 2 \mathrm{P}_{2}, 5 / 8 \mathrm{P}_{1}\right.$ $+3 / 8 \mathrm{P}_{2}$, and $\left.3 / 4 \mathrm{P}_{1}+1 / 4 \mathrm{P}_{2}\right)$, and a RRMLS with the spline polynomial knots adjusted to these same groups. The genetic parameters estimated through MULT and RRMLS did not differ from the simulated values. The correlations between BV (simulated and estimated) of animals were high and varied from 0.74 to 0.76 , which indicates the efficiency of using MULT and RRMLS for predicting $\mathrm{BV}$. Using field data, the traits age at first calving (AFC), first lactation length (LL), and 305-d milk yield (MY-305) from a multiple-breed population of Holstein-Gyr cattle were analyzed. The BV of animals were modeled through RRMLS with 3, 5, and 7 knots, distributed in accordance with the fraction of Holstein breed in each progeny breed group. It was verified that RRMLS with 7 knots for adjusting mean trajectories and genetic effects, with homogeneous residual variance, best fit AFC and LL. For MY-305, the best fit for mean trajectory and genetic effects was the RRMLS with 5 knots and with homogeneous residual variance. The posterior means of heritability varied from 0.21 to $0.48,0.21$ to 0.38 , and 0.10 to 0.33 for AFC, LL, and MY-305, respectively. Estimates from genetic parameters obtained by using RRMLS with field data showed

Received December 20, 2017.

Accepted July 4, 2018.

*Corresponding author: flbtoral@ufmg.br that this model is a useful tool for genetic evaluations of populations formed by a great number of breed groups. An interaction occurred between the BV of sires and their progeny breed group, and the genetic parameters for AFC, LL, and MY-305 traits from a multiple-breed population depend on breed composition of the progeny from which the evaluations are based.

Key words: crossing, dairy cattle, heritability, heterosis, selection

\section{INTRODUCTION}

The heterogeneity of variances and covariances among purebred and crossbred cows could occur in multiple breed populations (VanRaden et al., 2007) due to the use of different selection intensities and specific selection processes in groups with different genetic composition (Toral et al., 2012). Therefore, the development and implementation of genetic evaluations that account for genotypic means, genetic covariances among relatives (Lo et al., 1993), and the existence of specific genetic variances for each different breed group (Lukaszewicz et al., 2015) can contribute to the genetic improvement of multiple-breed populations. In addition, the identification of the interaction between progeny breed group and the breeding value $(\mathbf{B V})$ of sires (Vallée et al., 2013; Lukaszewicz et al., 2015) can help in designing mating strategies and improve genetic gain over generations.

Multiple-trait models (MULT) consider the same phenotype as different traits when measured in different breed groups and can incorporate heterogeneity of variances and covariances in multiple breed evaluations (Vallée et al., 2013; Lukaszewicz et al., 2015; Ribeiro et al., 2017). However, it is important to validate alternatives that can handle the genetic evaluation of multiple breed populations with several breed groups and with groups with few records. In this sense, the random regression models using linear splines (RRMLS; Misztal, 2006) can be applied in multiple-breed genetic evaluations as an alternative to MULT. 
In RRMLS, BV of selection candidates are obtained for specific points (knots) distributed along the gradient for a continuous variable of interest, so that the covariances and solutions of random regression coefficients directly represent the variances and BV for the traits of interest in each knot (Misztal, 2006). In this way, breed compositions can be expressed in multiple-breed genetic evaluations as a continuous variable, represented by the expected percentage of a particular breed for each animal with available data (Ribeiro et al., 2017). This means that solutions for the same trait are specific to the breed group, and the BV of sires are predicted regarding the specific breed group of the progeny. In addition, for breed groups in which the knots were not adjusted, BV estimates can be obtained by interpolation. This ensures less parameterization of the model and better data use compared with MULT. Therefore, we aimed to verify if RRMLS were suitable for obtaining genetic parameters in multiple breed populations and also to check the existence of interaction between the BV of sire and the progeny breed group.

\section{MATERIALS AND METHODS}

\section{Simulation}

To simulate a crossbreeding system, 2 breeds $\left(\mathrm{P}_{1}\right.$ and $\mathrm{P}_{2}$ ) were used. The mean for the simulated trait was 100 , the additive genetic variances of breeds $\mathrm{P}_{1}\left(\sigma_{a 1}^{2}\right)$ and $\mathrm{P}_{2}\left(\sigma_{a 2}^{2}\right)$ were 100 and 50, respectively, the segregation variance between breeds $\mathrm{P}_{1}$ and $\mathrm{P}_{2}$ was 20 , and residual variance $\left(\sigma_{e}^{2}\right)$ was 100 .

The evaluated groups were $1 / 2 \mathrm{P}_{1}+1 / 2 \mathrm{P}_{2}$ $\left(\mathbf{1} / \mathbf{2} \mathbf{P}_{1} \mathbf{P}_{\mathbf{2}}\right), 5 / 8 \mathrm{P}_{1}+3 / 8 \mathrm{P}_{2}\left(\mathbf{5} / \mathbf{8} \mathbf{P}_{\mathbf{1}} \mathbf{P}_{\mathbf{2}}\right)$, and $3 / 4 \mathrm{P}_{1}$ $+1 / 4 \mathrm{P}_{2}\left(\mathbf{3} / \mathbf{4} \mathbf{P}_{\mathbf{1}} \mathbf{P}_{\mathbf{2}}\right)$, formed by the daughters of $\mathrm{P}_{1}$, $5 / 8 \mathrm{P}_{1} \mathrm{P}_{2}$, and $3 / 4 \mathrm{P}_{1} \mathrm{P}_{2}$ sires. In this way, intermediate breed groups were formed to get the groups of interest.

The crossbreeding design was based on 2 purebreds $\mathrm{P}_{1}$ and $\mathrm{P}_{2}$, consisting of 960 animals each (Figure 1). Twenty-four sires from each base group and 80 dams from the $\mathrm{P}_{2}$ group were randomly selected. The $24 \mathrm{P}_{1}$ sires were mated to $80 \mathrm{P}_{2}$ dams to produce 480 offspring of the $\mathrm{F}_{1}$ generation, from which 40 dams were randomly selected. Twenty-four $\mathrm{P}_{2}$ sires and $40 \mathrm{~F}_{1}$ dams were mated to produce $1 / 4 \mathrm{P}_{1}+3 / 4 \mathrm{P}_{2}\left(1 / 4 \mathrm{P}_{1} \mathrm{P}_{2}\right)$ animals. To produce the group $3 / 4 \mathrm{P}_{1}+1 / 4 \mathrm{P}_{2}\left(3 / 4 \mathrm{P}_{1} \mathrm{P}_{2}\right), 24 \mathrm{P}_{1}$ sires and $40 \mathrm{~F}_{1}$ dams were also mated. Forty dams each from groups $1 / 4 \mathrm{P}_{1} \mathrm{P}_{2}$ and $3 / 4 \mathrm{P}_{1} \mathrm{P}_{2}$ and 12 sires from the $3 / 4 \mathrm{P}_{1} \mathrm{P}_{2}$ group were selected. To form the $7 / 8 \mathrm{P}_{1} \mathrm{P}_{2}$ and $5 / 8 \mathrm{P}_{1} \mathrm{P}_{2}$ groups, $24 \mathrm{P}_{1}$ sires were mated to $403 / 4 \mathrm{P}_{1} \mathrm{P}_{2}$ dams and $24 \mathrm{P}_{1}$ sires were mated to $401 / 4 \mathrm{P}_{1} \mathrm{P}_{2}$ dams, respectively, having $125 / 8 \mathrm{P}_{1} \mathrm{P}_{2}$ sires and 40 dams se- lected from each group. To form the $3 / 8 \mathrm{P}_{1}+5 / 8 \mathrm{P}_{2}$ group, $24 \mathrm{P}_{2}$ sires were mated to $403 / 4 \mathrm{P}_{1} \mathrm{P}_{2}$ dams, and from this group 40 dams were selected. The progenies $1 / 2 \mathrm{P}_{1} \mathrm{P}_{2}, 5 / 8 \mathrm{P}_{1} \mathrm{P}_{2}$, and $3 / 4 \mathrm{P}_{1} \mathrm{P}_{2}$, which are daughters of $5 / 8 \mathrm{P}_{1} \mathrm{P}_{2}$ sires, came from crossing $125 / 8 \mathrm{P}_{1} \mathrm{P}_{2}$ sires with 40 dams from each of the groups $3 / 8 \mathrm{P}_{1} \mathrm{P}_{2}, 5 / 8 \mathrm{P}_{1} \mathrm{P}_{2}$, and $7 / 8 \mathrm{P}_{1} \mathrm{P}_{2}$, respectively. Lastly, the progeny $1 / 2 \mathrm{P}_{1} \mathrm{P}_{2}$, $5 / 8 \mathrm{P}_{1} \mathrm{P}_{2}$, and $3 / 4 \mathrm{P}_{1} \mathrm{P}_{2}$, daughters from $3 / 4 \mathrm{P}_{1} \mathrm{P}_{2}$ sires, came from crossing between $123 / 4 \mathrm{P}_{1} \mathrm{P}_{2}$ sires with 40 dams from each of the groups $1 / 4 \mathrm{P}_{1} \mathrm{P}_{2}, \mathrm{~F} 1$, and 40 $3 / 4 \mathrm{P}_{1} \mathrm{P}_{2}$, respectively. It is important to point out that all selections were performed randomly.

It is also important to highlight that progenies belonging to group $1 / 2 \mathrm{P}_{1} \mathrm{P}_{2}$, daughters of $\mathrm{P}_{1}, 5 / 8 \mathrm{P}_{1} \mathrm{P}_{2}$, or $3 / 4 \mathrm{P}_{1} \mathrm{P}_{2}$ sires, do not necessarily have the same variances. The same is true for the progenies $5 / 8 \mathrm{P}_{1} \mathrm{P}_{2}$ and $3 / 4 \mathrm{P}_{1} \mathrm{P}_{2}$ daughters of $\mathrm{P}_{1}, 5 / 8 \mathrm{P}_{1} \mathrm{P}_{2}$, or $3 / 4 \mathrm{P}_{1} \mathrm{P}_{2}$ sires. This happens because the additive genetic (co)variance matrix $\mathbf{G}(\varphi)$ is a function of breed-specific and segregation dispersion parameters in $\varphi$ for crossbred populations. Thus, the segregation can vary among groups with the same genetic composition due to different parent groups. Cardoso and Tempelman (2004) described a hierarchical Bayes model, based on the multiple-breed model presented by Lo et al. (1993), for estimating fixed and genetic effects when the breed segregation components are unknown.

Lo et al. (1993) suggested that $\mathbf{G}(\varphi)$ elements may be calculated by a tabular method, having the jth diagonal element determined as

$$
\begin{aligned}
\operatorname{Var}\left(a_{j}\right)= & \sum_{b=1}^{B} f_{b}^{j} \sigma_{A_{b}}^{2}+\sum_{b=1}^{B-1} \sum_{b^{\prime}>b}^{B} 2\left(f_{b}^{s} f_{b^{\prime}}^{s}+f_{b}^{d} f_{b^{\prime}}^{d}\right) \sigma_{S_{b b^{\prime}}}^{2} \\
& +0.5 \operatorname{cov}\left(a_{j}^{s} a_{j}^{d}\right)
\end{aligned}
$$

for $j=1,2, \ldots, \mathrm{q}$, where $B$ denotes the breed(s) $b$ and $b^{\prime}$, for $b=1, \ldots, B ; b^{\prime}=b+1, \ldots, \mathrm{B} ; b<b^{\prime}$ for which the effects were estimated; $f_{b}^{j}, f_{b}^{s}$, and $f_{b}^{d}$ represent, respectively, the individual, sire, and dam proportions of alleles from breed $b ; a_{j}^{s}$ and $a_{j}^{d}$ denote an additive genetic effect of animal $j$ 's sire and dam; $\sigma_{A_{b}}^{2}$ is the additive genetic variance of breed $b ; \sigma_{S_{b b^{\prime}}}^{2}$ is the variance due to segregation among $b$ and $b^{\prime}$ breeds. In summary, $\varphi=\left[\left(\sigma_{A_{b}}^{2}\right)_{b=1^{\prime}}^{B}\left(\sigma_{S_{b b^{\prime}}}^{2}\right)_{b=1, b^{\prime}>b}^{B-1, B}\right]$ defines all genetic components of variance. Quaas (1988) and Lo et al. (1993) showed that the inverse of $\mathbf{G}(\varphi)$ can be calculated by using $\left[(\mathbf{G}(\varphi)]^{-1}=(\mathbf{I}-\mathbf{P})^{\prime}[\Omega(\varphi)]^{-1}(\mathbf{I}-\mathbf{P})\right.$, where $\mathbf{I}$ is an identity matrix, $\mathbf{P}$ is a matrix relating progeny to parents, and $\Omega(\varphi)$ is a diagonal matrix with the $j$ th diagonal element defined as 


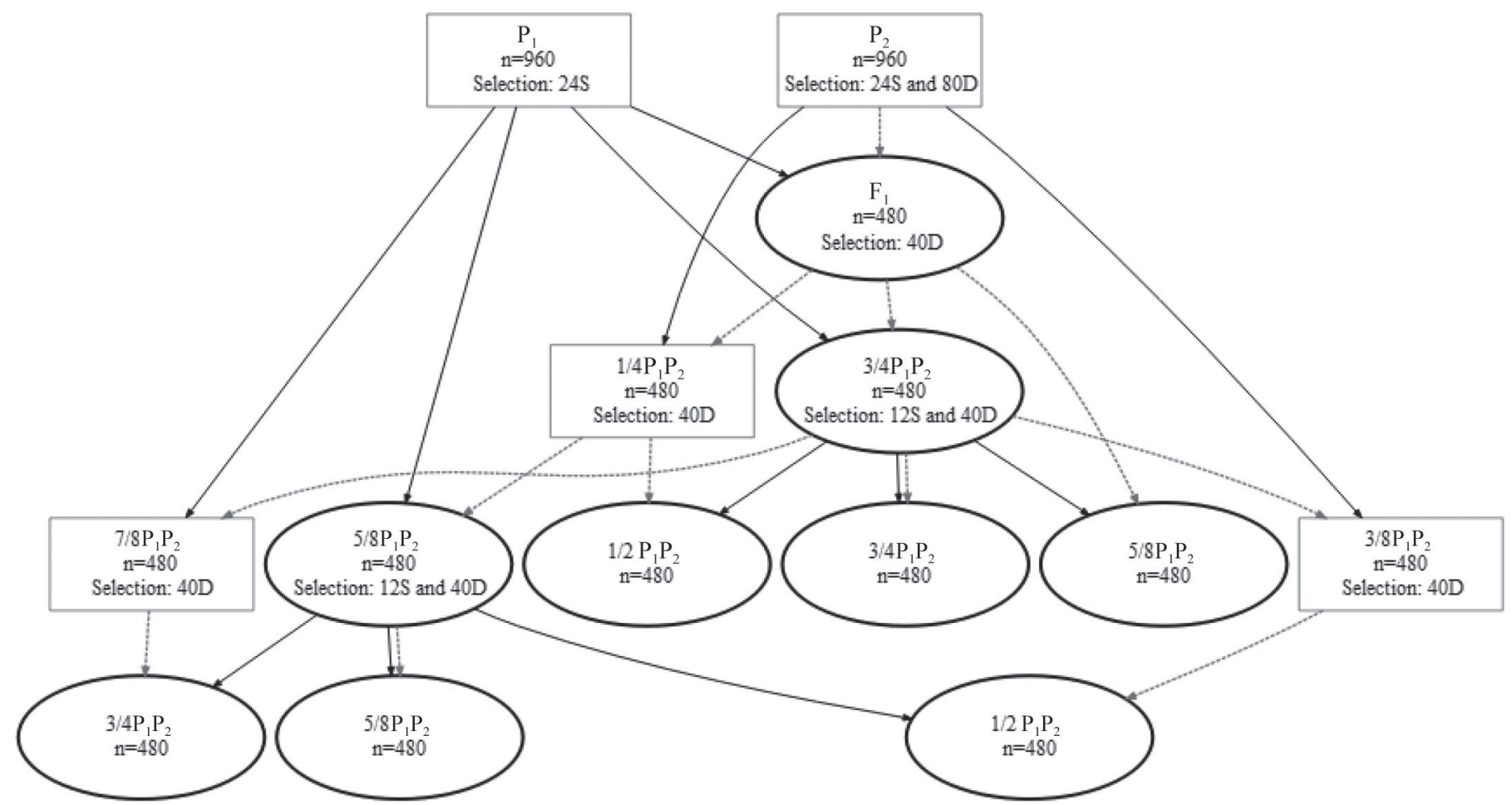

Figure 1. Crossing design between 2 purebreds $\left(\mathrm{P}_{1}\right.$ and $\left.\mathrm{P}_{2}\right)$ and their crosses. Black and continuous lines represent paths of sires, and gray and dotted lines represent paths of dams. The letters $\mathrm{S}$ and $\mathrm{D}$ represent the selection of sires and dams, respectively, along with the number of animals selected in each case. The groups with different genetic composition with phenotypic records are represented.

$\omega_{j}=\operatorname{Var}\left(a_{j}\right)-0,25\left[\operatorname{Var}\left(a_{j}^{s}\right)+\operatorname{Var}\left(a_{j}^{d}\right)\right]-0,5 \operatorname{cov}\left(a_{j}^{s}, a_{j}^{d}\right)$, being a linear function of $\varphi$ elements. Further information on the simulation process is available in Cardoso and Tempelman (2004).

In the simulation process, inbreeding was avoided in all matings and sex was randomly defined with equal probability for each offspring. For each animal, just 1 phenotypic record was generated based on a model with mixed effects, including the general average $(\mu=$ 100) and additive and nonadditive (segregation) fixed genetic effects, represented by $\gamma_{A_{\mathrm{P}_{1}}}=25$ and $\gamma_{A_{\mathrm{P}_{2}}}=0$ for the additive effects of $\mathrm{P}_{1}$ and $\mathrm{P}_{2}$, respectively, $\gamma_{D_{\mathrm{P}_{1} \mathrm{P}_{2}}}$ $=0$ for the dominance effect and $\gamma_{A A_{\mathrm{P}_{1} \mathrm{P}_{2}}}=0$ for the segregation effect. Random residual effects were distributed in an identical and independent way. The additive genetic effect of animal $j$ was generated by using $a_{j}=0.5 a_{j}^{s}+0.5 a_{j}^{d}+z_{j} \sqrt{\omega_{j}}$, where $z_{j} \sim N(0,1)$ with $\omega_{j}$ as defined in the previous equation, for $j=1,2, \ldots$, 32,000 animals. Parental contributions $a_{j}^{s}$ and $a_{j}^{d}$ were null when the parents were not identified, as in case of base population animals, such that $\omega_{j}$ is the corresponding breed-specific additive genetic variance. This simulation process was performed 10 times.

\section{Models}

To analyze the simulated data, a multiple-trait model (MULT) with 3 traits was used. In this model, the same phenotype, when analyzed in the groups $1 / 2 \mathrm{P}_{1} \mathrm{P}_{2}$, $5 / 8 \mathrm{P}_{1} \mathrm{P}_{2}$, and $3 / 4 \mathrm{P}_{1} \mathrm{P}_{2}$, was considered as 3 distinct traits.

The MULT can be represented as $y_{h j}=m_{h}+b_{1} \mathrm{P}_{1 j}$ $+a_{j}+e_{h j}$, in which $y_{h j}$ is the phenotype of trait $h$ in the $j$ th animal; $m_{h}$ represents the mean of trait $h ; b_{1}$ represents the regression coefficient that adjust the effect of proportion of alleles derived from $\mathrm{P}_{1}$ group; $\mathrm{P}_{1 j}$ represents the proportion of $\mathrm{P}_{1}$ derived alleles of animal $j ; a_{j}$ represents the additive $\mathrm{BV}$ of animal $j$; and $e_{h j}$ is the error associated with each observation.

In matrix notation, the following general model was used in the 3-trait analyses:

$$
\left[\begin{array}{l}
\mathbf{y}_{\mathbf{1}} \\
\mathbf{y}_{\mathbf{2}} \\
\mathbf{y}_{\mathbf{3}}
\end{array}\right]=\left[\begin{array}{ccc}
\mathbf{X}_{1} & \Phi & \Phi \\
\Phi & \mathbf{X}_{2} & \Phi \\
\Phi & \Phi & \mathbf{X}_{3}
\end{array}\right]\left[\begin{array}{l}
\boldsymbol{\beta}_{1} \\
\boldsymbol{\beta}_{2} \\
\boldsymbol{\beta}_{3}
\end{array}\right]+\left[\begin{array}{ccc}
\mathbf{Z}_{1} & \Phi & \Phi \\
\Phi & \mathbf{Z}_{2} & \Phi \\
\Phi & \Phi & \mathbf{Z}_{3}
\end{array}\right]\left[\begin{array}{l}
\mathbf{a}_{\mathbf{1}} \\
\mathbf{a}_{\mathbf{2}} \\
\mathbf{a}_{\mathbf{3}}
\end{array}\right]+\left[\begin{array}{l}
\mathbf{e}_{\mathbf{1}} \\
\mathbf{e}_{\mathbf{2}} \\
\mathbf{e}_{\mathbf{3}}
\end{array}\right],
$$

where $\mathbf{y}_{\mathbf{h}}$ is the observation vector of $\mathbf{h}$ trait $(\mathbf{h}=$ Trait- $1 / 2 \mathrm{P}_{1} \mathrm{P}_{2}$, Trait-5/8 $\mathrm{P}_{1} \mathrm{P}_{2}$, and Trait- $\left.3 / 4 \mathrm{P}_{1} \mathrm{P}_{2}\right) ; \mathbf{X}_{\mathbf{h}}$ 
is the incidence matrix of fixed effects of the trait (alleles from $\left.\mathrm{P}_{1}\right) \mathbf{h} ; \boldsymbol{\beta}_{\mathbf{h}}$ is the solution vector for fixed effects; $\mathbf{Z}_{\mathrm{h}}$ is the incidence matrix of direct additive genetic effects; $\mathbf{a}_{\mathbf{h}}$ is the solution vector for direct additive genetic effects; and $\mathbf{e}_{\mathbf{h}}$ is the error vector.

For the RRMLS, 3 knots were used, one for each group: $1 / 2 \mathrm{P}_{1} \mathrm{P}_{2}, 5 / 8 \mathrm{P}_{1} \mathrm{P}_{2}$, and $3 / 4 \mathrm{P}_{1} \mathrm{P}_{2}$. The residual variance was considered heterogeneous and consisted of 3 classes defined according to the groups where the knots were adjusted. Thus, each breed group $\left(1 / 2 \mathrm{P}_{1} \mathrm{P}_{2}\right.$, $5 / 8 \mathrm{P}_{1} \mathrm{P}_{2}$, and $\left.3 / 4 \mathrm{P}_{1} \mathrm{P}_{2}\right)$ had a specific residual variance, enabling comparison with the ones estimated by the MULT for the same groups.

In fitting RRMLS the expected proportion from $\mathrm{P}_{1}$ breed was converted into the covariable $\left[\varphi_{1}\left(\mathrm{P}_{1}\right)\right]$. Considering $n$ knots in $T_{i}$ points $(i=1, \ldots, n)$, and $T_{i} \leq t$ $<T_{i}+1$, the covariables can be obtained at $i$ and $i+$ 1 knots, through the equations $\varphi_{i}(t)=\frac{T_{i+1}-t}{T_{i+1}-T_{i}}$ and $\varphi_{i+1}(t)=1-\frac{T_{i+1}-t}{T_{i+1}-T_{i}}$, respectively. For other values out of the $T_{i}$ and $T_{i+1}$ interval, $\varphi_{i}(t)=0$. Assuming that data points occur only at knots and that observation $k$ (different breed groups) occurs at knot $\varphi_{i}\left(T_{k}\right)=\left\{\begin{array}{lll}1 & \text { if } & i=k \\ 0 & \text { if } & i \neq k\end{array}\right.$. Three knots were adjusted precisely at the groups and the genetic parameters as (co) variances and breeding values were obtained directly from the analyses results.

The genetic composition effect $\left(\mathrm{P}_{1}\right.$, linear covariable) was included in the model and the RRMLS can be represented as $y_{k l m}=m_{k}+b_{1\left(\mathrm{P}_{1}\right)}+\sum_{\mathrm{P}_{1}=1}^{3} a_{m\left(\mathrm{P}_{1}\right)} \varphi_{\mathrm{P}_{1}}\left(\mathrm{P}_{\mathrm{1}_{l}}\right)+e_{k l m}$, where $m_{k}$ represents the mean of trait $k ; b_{1\left(\mathrm{P}_{1}\right)}$ the regression coefficient associated with the proportional effects of alleles $\mathrm{P}_{1} ; 3$ coefficient represents the number of knots for adjusting this effect; $\varphi_{\mathrm{P}_{1}}\left(\mathrm{P}_{1_{l}}\right)$ is the respective splines associated with knots of $\mathrm{P}_{1} ; a_{m\left(\mathrm{P}_{1}\right)}$ is the additive genetic random regression coefficient of the animal $m$ associated with the knot $\mathrm{P}_{1}$; and $e_{k l m}$ is the associated error at each observation. Other terms are in accordance with the previous description.

In its matrix form, the random regression model used can be represented by $\mathbf{y}=\mathbf{X} \boldsymbol{\beta}+\mathbf{Z} \mathbf{a}+\mathbf{e}$, where $\mathbf{y}$ represents the vector with the observed phenotypes; $\mathbf{X}$ represents the incidence matrix of fixed effects; $\boldsymbol{\beta}$ is the solution vector for fixed effects; $\mathbf{Z}$ is the incidence matrix of spline coefficients to model direct additive genetic effects; $\mathbf{a}$ is the solution vector for random regression coefficients of direct additive genetic effects; and $\mathbf{e}$ is the random residual.
The following assumptions were considered for the effects included in the MULT model $\left[\begin{array}{lll}\boldsymbol{\beta}_{1} & \boldsymbol{\beta}_{2} & \boldsymbol{\beta}_{3}\end{array}\right]^{t} \sim$ constant;

$\left[\begin{array}{lll}\mathbf{a}_{1} & \mathbf{a}_{2} & \mathbf{a}_{3}\end{array}\right]^{t} \mid \mathbf{A}, \mathbf{G}_{0} \sim N\left(\left[\begin{array}{lll}0 & 0 & 0\end{array}\right]^{t}, \mathbf{G}_{0} \otimes \mathbf{A}\right), \quad$ and $\left[\begin{array}{lll}\mathbf{e}_{1} & \mathbf{e}_{2} & \mathbf{e}_{3}\end{array}\right]^{t} \mid \mathbf{R}_{0} \sim N\left(\left[\begin{array}{lll}0 & 0 & 0\end{array}\right]^{t}, \mathbf{R}_{0} \otimes \mathbf{I}\right)$, where $\mathbf{A}$ represents the additive genetic relationship matrix among the animals; $\mathbf{G}_{0}$ is the additive genetic covariances matrix among the traits, such that

$$
\mathbf{G}_{\mathrm{a} 0}=\left[\begin{array}{ccc}
\sigma_{\mathrm{a} 1}^{2} & \sigma_{\mathrm{a} 12} & \sigma_{\mathrm{a} 13} \\
\sigma_{\mathrm{a} 12} & \sigma_{\mathrm{a} 2}^{2} & \sigma_{\mathrm{a} 23} \\
\sigma_{\mathrm{a} 13} & \sigma_{\mathrm{a} 23} & \sigma_{\mathrm{a} 3}^{2}
\end{array}\right] ;
$$

$N$ refers to a normal distribution; $\otimes$ is the direct product operator among matrices; $\mathbf{R}_{0}$ is the residual variance matrix for the traits, such that

$$
\mathbf{R}_{\mathrm{e} 0}=\left[\begin{array}{ccc}
\sigma_{\mathrm{e} 11}^{2} & 0 & 0 \\
0 & \sigma_{\mathrm{e} 22}^{2} & 0 \\
0 & 0 & \sigma_{\mathrm{e} 33}^{2}
\end{array}\right]
$$

and $\mathbf{I}$ is an identity matrix with the same order as the number of observations, and $\sigma_{\mathrm{a}}^{2}$ represents the additive genetic variance and $\sigma_{\mathrm{e}}^{2}$ represents the residual variance. The following a priori assumptions were considered for RRMLS model: $\boldsymbol{\beta} \sim$ constant, $\mathbf{a} \mid \mathbf{A}, \mathbf{G}_{0}^{*} \sim N\left(0, \mathbf{G}_{0}^{*} \otimes \mathbf{A}\right)$, and $\mathbf{e} \mid \mathbf{R}^{*} \sim N\left(0, \mathbf{R}^{*}\right)$. In both models (MULT and RRMLS), inverted Wishart distributions were assumed for both genetic and residual covariance matrices, being $\mathbf{G}_{0}$ and $\mathbf{G}_{0}^{*} \sim \mathbf{I W}\left(\Sigma_{\mathbf{a}}^{2}, \mathbf{n}_{\mathbf{a}}\right)$, and $\mathbf{R}_{0} \sim \mathbf{I W}\left(\Sigma_{\mathbf{e}}^{\mathbf{2}}, \mathbf{n}_{\mathbf{e}}\right)$, where $\Sigma_{\mathbf{a}}^{2}, \Sigma_{\mathbf{e}}^{2}, \mathbf{n}_{\mathbf{a}}$, and $\mathbf{n}_{\mathbf{e}}$ represent hyperparameters of the inverted Wishart distributions. Additional information about this Bayesian implementation, including fully conditional posterior distributions is available in Sorensen and Gianola (2002).

Samples of the fully conditional distributions of covariance components were obtained by Gibbs sampling using the GIBBS3F90 program (Misztal et al., 2014). Chains of 550,000 samples were obtained, with initial burn-in of 50,000 samples and samplings of covariance component values at each 50 cycles. The size of the chain was determined by the preliminary analyses according to Raftery and Lewis (1992), which is available in the BOA package (Smith, 2005) of the R software (R Core Team, 2015). The convergence of post-burn-in chains was evaluated by means of the criterion proposed by Geweke (1992), which is also available in the 
Table 1. Crossing design of sires and dams from different breeds, and the respective progeny breed group $(\mathrm{P}),{ }^{1}$ and number of records ${ }^{2}$ to age at first calving (AFC), lactation length (LL) and 305-d milk yield (MY-305) of the first lactation in a multiple breed population Holstein (H)Gyr $(\mathrm{G})$

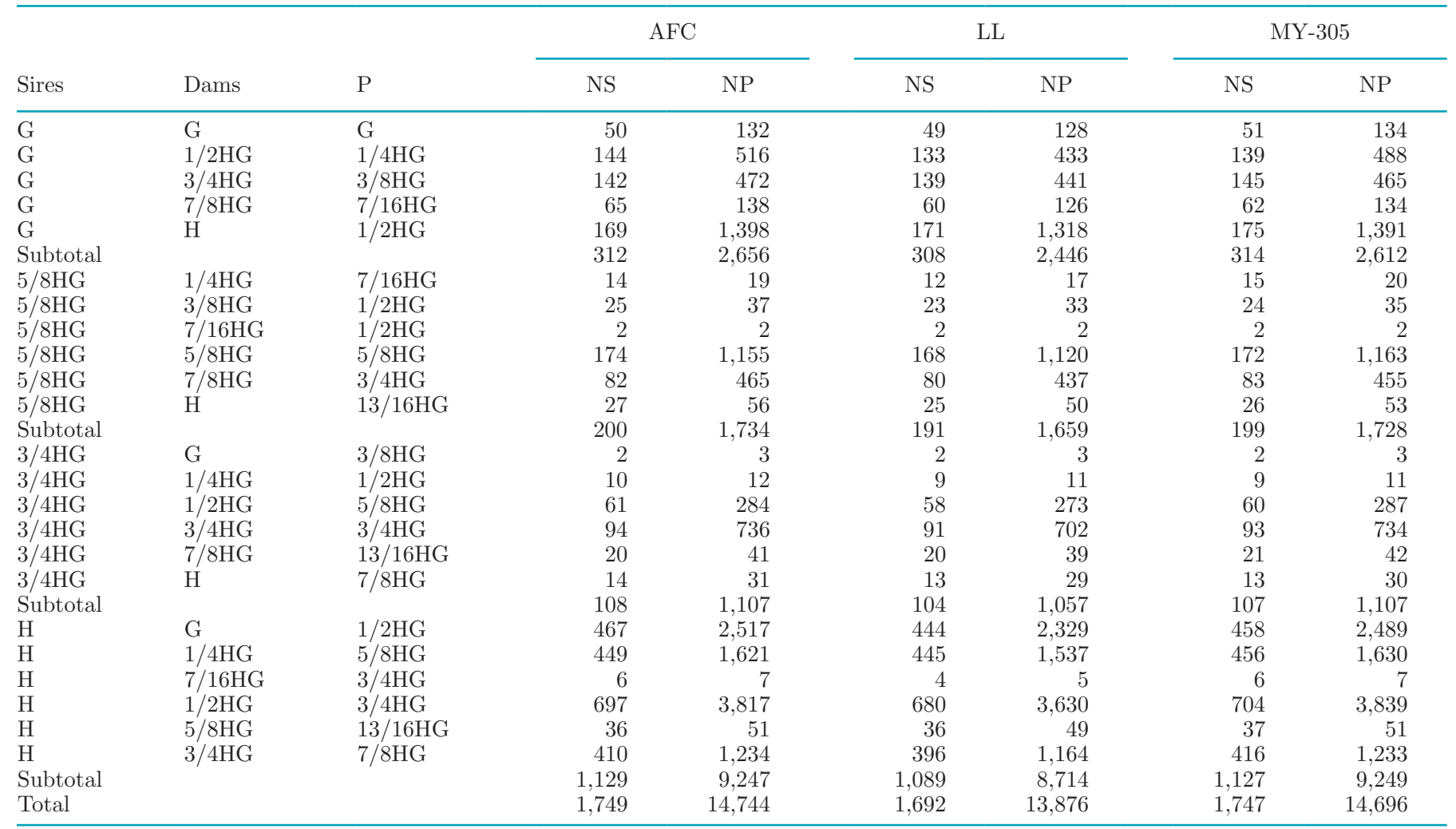

${ }^{1}$ The fraction in front of the initials HG represents the expected percentage of Holstein alleles.

${ }^{2} \mathrm{NS}=$ number of sires; NP = number of progeny.

BOA package and by visual inspection of trace plots of the sampled values by iteration.

\section{Application to Field Data}

The phenotypic data came from the Record System of the Brazilian Association of Girolando, managed by Embrapa Dairy Cattle (Juiz de Fora, Minas Gerais, Brazil). The analyzed traits were age at first calving (AFC), first lactation length (LL), and 305-d milk yield (MY-305). The breed composition of dams with phenotypic records (Tables 1 and 2) varied from purebred Gyr to $7 / 8$ Holstein $+1 / 8$ Gyr $(7 / 8 \mathrm{HG})$.

Only the records of the dams with AFC between 560 and $1,650 \mathrm{~d}$ that were born from 1997 to 2010 and gave birth between 1998 and 2013 were considered. Moreover, data were limited to those lactations that were ended due to low production or calving proximity without any abnormality record. Only data from contemporary groups with at least 3 records and daughters from at least 2 sires were considered (Table 2). Contemporary groups were formed according to herd and year of birth (for AFC) and herd and year of calving (for LL and MY-305).

Sires from 4 breed groups were evaluated: Gyr, 5/8 Holstein $+3 / 8$ Gyr $(5 / 8 \mathrm{HG}), 3 / 4$ Holstein $+1 / 4$ Gyr $(3 / 4 \mathrm{HG})$, and Holstein (Table 1$)$. For the multiplebreed genetic evaluation of the different groups, 6 RRMLS were used to adjust the genetic additive effects regarding the breed composition of the animals.

The knot positions (Table 3) were defined in accordance with the matings and the number of observations found in each breed group. Homogeneous and heterogeneous residual variances were considered for the models with 3, 5, and 7 knots. According to the group and by the number of observations in each class, 2 residual classes were formed. The first group included animals from Gyr to $5 / 8 \mathrm{HG}$ and the second group from $3 / 4 \mathrm{HG}$ to $7 / 8 \mathrm{HG}$.

The mean trajectories [a genetic composition effect over the traits of interest $(\mathrm{PHol})]$ were also adjusted by RRMLS, having the knots on the same points defined for adjusting the genetic effects. The breed composition effects (PHol, linear covariate), heterozygosity propor- 
Table 2. Summary statistics of age at first calving, lactation length, and 305-d milk yield of first lactation from a multiple breed population Holstein $(\mathrm{H})$-Gyr $(\mathrm{G})$

\begin{tabular}{|c|c|c|c|c|c|}
\hline Group $^{1}$ & Number of records & Mean & $\mathrm{SD}$ & Minimum & Maximum \\
\hline \multicolumn{6}{|c|}{ Age at first calving } \\
\hline Gyr & 132 & 1,161 & 168 & 804 & 1,539 \\
\hline $1 / 8 \mathrm{HG}$ & 516 & 1,156 & 164 & 737 & 1,619 \\
\hline $3 / 8 \mathrm{HG}$ & 475 & 1,163 & 159 & 600 & 1,581 \\
\hline $7 / 16 \mathrm{HG}$ & 157 & 1,098 & 152 & 785 & 1,442 \\
\hline $1 / 2 \mathrm{HG}$ & 3,966 & 1,025 & 187 & 564 & 1,637 \\
\hline $5 / 8 \mathrm{HG}$ & 3,060 & 1,075 & 192 & 590 & 1,619 \\
\hline $3 / 4 \mathrm{HG}$ & 5,025 & 1,040 & 191 & 574 & 1,611 \\
\hline $13 / 16 \mathrm{HG}$ & 148 & 990 & 184 & 713 & 1,452 \\
\hline $7 / 8 \mathrm{HG}$ & 1,265 & 1,045 & 186 & 562 & 1,645 \\
\hline \multicolumn{6}{|c|}{ Lactation length } \\
\hline Gyr & 128 & 262 & 90 & 77 & 491 \\
\hline $1 / 8 \mathrm{HG}$ & 433 & 256 & 96 & 61 & 563 \\
\hline $3 / 8 \mathrm{HG}$ & 444 & 258 & 98 & 63 & 635 \\
\hline $7 / 16 \mathrm{HG}$ & 143 & 271 & 105 & 61 & 681 \\
\hline $1 / 2 \mathrm{HG}$ & 3,693 & 277 & 94 & 61 & 684 \\
\hline $5 / 8 \mathrm{HG}$ & 2,930 & 274 & 100 & 61 & 695 \\
\hline $3 / 4 \mathrm{HG}$ & 4,774 & 301 & 106 & 61 & 700 \\
\hline $13 / 16 \mathrm{HG}$ & 138 & 299 & 84 & 110 & 573 \\
\hline $7 / 8 \mathrm{HG}$ & 1,193 & 315 & 115 & 62 & 700 \\
\hline \multicolumn{6}{|c|}{ 305-d milk yield } \\
\hline Gyr & 134 & 2,582 & 1,192 & 329 & 6,153 \\
\hline $1 / 8 \mathrm{HG}$ & 488 & 3,188 & 2,258 & 202 & 12,428 \\
\hline $3 / 8 \mathrm{HG}$ & 468 & 3,352 & 2,051 & 220 & 10,879 \\
\hline $7 / 16 \mathrm{HG}$ & 154 & 3,719 & 2,123 & 289 & 10,252 \\
\hline $1 / 2 \mathrm{HG}$ & 3,928 & 4,251 & 2,278 & 200 & 16,255 \\
\hline $5 / 8 \mathrm{HG}$ & 3,080 & 3,585 & 1,998 & 200 & 14,202 \\
\hline $3 / 4 \mathrm{HG}$ & 5,035 & 4,492 & 2,082 & 200 & 14,088 \\
\hline $13 / 16 \mathrm{HG}$ & 146 & 4,472 & 2,047 & 296 & 8,868 \\
\hline $7 / 8 \mathrm{HG}$ & 1,263 & 4,667 & 2,189 & 235 & 12,228 \\
\hline
\end{tabular}

${ }^{1}$ The fraction in front of the initials HG represents the expected percentage of Holstein alleles.

tion (PHet, adjusted by linear splines with 5 knots), and the effect of dam's age at calving (linear and quadratic terms of the covariate) were included in the model. For AFC, the contemporary group effects (herd and year of birth) and month of birth were also considered. For LL and MY-305, the contemporary group effects (herd and year of calving) and month of calving were considered.

The expected proportion of the Holstein breed alleles in each animal (PHol) and the heterozygosis proportion (PHet) were computed in a recursive way from the oldest ancestor. The expected proportion of heterozygosis (PHet) was obtained by the following expression: PHet

Table 3. Knots position of random regression models in analyses of age at first calving (AFC), lactation length (LL) and 305-day milk yield (MY-305) of the first lactation in Holstein (H)-Gyr $(\mathrm{G})$ multiple breed population

\begin{tabular}{ll}
\hline Knots & Knots position $^{1}$ \\
\hline 3 & Gyr, $1 / 2 \mathrm{HG}, 7 / 8 \mathrm{HG}$ \\
5 & Gyr, $1 / 4 \mathrm{HG}, 1 / 2 \mathrm{HG}, 3 / 4 \mathrm{HG}, 7 / 8 \mathrm{HG}$ \\
7 & Gyr, $3 / 8 \mathrm{HG}, 1 / 4 \mathrm{HG}, 1 / 2 \mathrm{HG}, 5 / 8 \mathrm{HG}, 3 / 4 \mathrm{HG}, 7 / 8 \mathrm{HG}$ \\
\hline
\end{tabular}

${ }^{1}$ The fraction in front of the initials HG represents the percentage of Holstein alleles.
$=P_{\mathrm{PHol}} s \times\left(1-P_{\mathrm{PHol}} d\right)+P_{\mathrm{PHol}} d \times\left(1-P_{\mathrm{PHol}} s\right)$, in which PHet is the heterozygosis proportion of the individual of interest; $P_{\mathrm{PHol}} s$ is the expected proportion of derived alleles from $\mathrm{PHol}$ of the sire, and $P_{\mathrm{PHol}} d$ is the expected proportion of alleles coming from $\mathrm{PHol}$ of the dam.

The numerator relationship matrix (A) considered pedigree data on 39,144 animals. The same prior distributions that were assumed for RRMLS applied to the simulated data file were assumed for the field data analysis. It is important to highlight that some covariances from matrix $\mathbf{G}_{0}$ were zero because it is impossible for sires to have daughters in all breed groups.

Bayesian estimation involved chains of $1,100,000$ cycles with initial burn-in of 100,000 cycles and samples of covariance component values at each 100 cycles and convergence analysis was identical to that described above for the simulated data.

Comparisons among the models were performed based on the deviance information criterion (DIC) proposed by Spiegelhalter et al. (2002): DIC $=2 \bar{D}(\theta)-D(\bar{\theta})$, where $D(\bar{\theta})=E_{\theta \mid y}[D(\theta)]$ represents a posteriori expectation of Bayesian deviations and $D(\bar{\theta})=-2 \log p(y \mid \theta)$ indicates the adjustment for this model. 
Table 4. Posterior means and highest posterior density intervals ${ }^{1}$ with $90 \%$ of samples (in brackets), obtained by means of models multiple trait and random regression with linear splines, of additive genetic $\left(\sigma_{a}^{2}\right)$ and residual $\left(\sigma_{e}^{2}\right)$ variances, heritabilities $\left(\mathrm{h}^{2}\right)$, and Spearman correlations $\left(r_{t x a}\right)$ with SD (in brackets) among the simulated and EBV

\begin{tabular}{|c|c|c|c|c|}
\hline Group $^{2}$ & $\sigma_{a}^{2}$ & $\sigma_{e}^{2}$ & $\mathrm{~h}^{2}$ & $r_{t x a}$ \\
\hline \multicolumn{5}{|c|}{ Simulated values } \\
\hline $1 / 2 \mathrm{P}_{1} \mathrm{P}_{2}$ & 75.00 & 100.00 & 0.42 & - \\
\hline $3 / 4 \mathrm{P}_{1} \mathrm{P}_{2}$ & 87.50 & 100.00 & 0.46 & - \\
\hline \multicolumn{5}{|c|}{ Estimated by multiple trait model } \\
\hline $1 / 2 \mathrm{P}_{1} \mathrm{P}_{2}$ & $\begin{array}{l}81.36 \\
(53.63 ; 107.00)\end{array}$ & $\begin{array}{l}106.71 \\
(87.04 ; 126.50)\end{array}$ & $\begin{array}{l}0.43 \\
(0.31 ; 0.54)\end{array}$ & $0.74(0.04)$ \\
\hline $3 / 4 \mathrm{P}_{1} \mathrm{P}_{2}$ & $\begin{array}{l}99.53 \\
(64.34 ; 135.40)\end{array}$ & $\begin{array}{l}104.60 \\
(82.36 ; 127.20)\end{array}$ & $\begin{array}{l}0.48 \\
(0.34 ; 0.61)\end{array}$ & $0.76(0.04)$ \\
\hline \multicolumn{5}{|c|}{ Estimated by random regression model with linear splines } \\
\hline $1 / 2 \mathrm{P}_{1} \mathrm{P}_{2}$ & $\begin{array}{l}90.44 \\
(60.70 ; 119.10)\end{array}$ & $\begin{array}{l}101.42 \\
(80.57 ; 126.20)\end{array}$ & $\begin{array}{l}0.46 \\
(0.34 ; 0.58)\end{array}$ & $0.76(0.04)$ \\
\hline $5 / 8 \mathrm{P}_{1} \mathrm{P}_{2}$ & $\begin{array}{l}98.69 \\
(66.69 ; 128.10)\end{array}$ & $\begin{array}{l}105.10 \\
(84.82 ; 126.20)\end{array}$ & $\begin{array}{l}0.48 \\
(0.35 ; 0.60)\end{array}$ & $0.76(0.04)$ \\
\hline
\end{tabular}

${ }^{1}$ The posteriori means and the highest posterior density intervals of the 10 simulated files.

${ }^{2}$ The fraction in front of the term $\mathrm{P}_{1} \mathrm{P}_{2}$ represents the expected percentage of $\mathrm{P}_{1}$ alleles.

To check for an interaction between the BV of sire and the progeny breed group from which it was evaluated, we considered the covariance structure between the progeny breed group and the rank of 3 sires from Gyr, 5/8HG, 3/4HG, and Holstein groups with greater number of daughters according to the estimated BV for the progeny breed group.

\section{RESULTS}

\section{Simulation}

For both models (MULT and RRMLS), posterior means of additive genetic and residual variances and heritability were similar to the simulated values, with the highest posterior density intervals overlapping (Table 4). High Spearman correlations, between 0.74 and 0.76 , were obtained among the simulated and estimated BV for animals with records (Table 4).

Among the top $10 \%$ of the animals, the percentage of sires in common for simulated and estimated data varied from 50 to $72 \%$ in the MULT and from 50 to $74 \%$ in the RRMLS (Table 5). Among the top 5\% sires, this proportion varied from 60 to $87 \%$ and from 59 to $90 \%$ in MULT and RRMLS, respectively.

\section{Field Data}

For adjusting the mean trajectories and additive genetic effects, the RRMLS with 7 knots and homogeneous residual variance showed the best adjustment for AFC and LL (Table 6). For MY-305, the model that showed the best adjustment was the one with 5 knots for mean trajectories and genetic effects and homogeneous residual variance. The lower and upper limits of the highest density intervals of residual variances for AFC, LL, and MY-305 were 13.62 and 15.36 $\mathrm{d}^{2}, 57.25$ and $63.46 \mathrm{~d}^{2}$, and $1,638.00$ and $1,818.00 \mathrm{~kg}^{2}$, respectively.

In general, with increasing allele percentage from the Holstein breed, the posterior means of genetic variances and heritability for AFC decreased (Figure 2). For LL, the genetic variances and heritability were constant among groups Gyr and 5/8HG, as overlapping of the highest density intervals occurred, and they tended to be greater for groups with a Holstein proportion higher than $5 / 8 \mathrm{HG}$. The highest posterior means of variances and heritability for MY-305 were achieved in group $1 / 2 \mathrm{HG}$ and the lowest ones in the Gyr and 3/4HG groups. These results suggest that, given the same selection intensity, the responses to selection could differ among the progeny breed groups.

Overall, the correlations among random regression coefficients used for adjusting BV for AFC, LL, and MY-305 in the different breed groups were null (Table $7)$. In these cases, the $\mathrm{BV}$ and the sire ranking from Gyr, $5 / 8 \mathrm{HG}, 3 / 4 \mathrm{HG}$, and Holstein groups was not the same, which shows that the BV and sire raking depend on the progeny breed group by which the BV of sire was estimated. On the other hand, it was observed that the $\mathrm{BV}$ of some sires were almost constant, independent of the progeny breed group (Figure 3 ). 
Table 5. Proportion of sires selected in common by the simulated results and those obtained by multipletrait model (MULT) or random regression models with linear spline polynomials (RRMLS) when selecting 5 or $10 \%$ (top $5 \%$ and top 10\%, respectively) of the highest breeding values according to the different progeny breed groups

\begin{tabular}{|c|c|c|c|c|c|c|}
\hline \multirow[b]{3}{*}{ Sires $^{1}$} & \multicolumn{6}{|c|}{ Progeny breed composition ${ }^{1}$} \\
\hline & \multicolumn{3}{|c|}{ MULT } & \multicolumn{3}{|c|}{ RRMLS } \\
\hline & $1 / 2 \mathrm{P}_{1} \mathrm{P}_{2}$ & $5 / 8 \mathrm{P}_{1} \mathrm{P}_{2}$ & $3 / 4 \mathrm{P}_{1} \mathrm{P}_{2}$ & $1 / 2 \mathrm{P}_{1} \mathrm{P}_{2}$ & $5 / 8 \mathrm{P}_{1} \mathrm{P}_{2}$ & $3 / 4 \mathrm{P}_{1} \mathrm{P}_{2}$ \\
\hline \multicolumn{7}{|l|}{ Top $10 \%$} \\
\hline $5 / 8 \mathrm{P}_{1} \mathrm{P}_{2}$ & 63 & 63 & 62 & 65 & 64 & 64 \\
\hline $3 / 4 \mathrm{P}_{1} \mathrm{P}_{2}$ & 72 & 70 & 70 & 74 & 72 & 72 \\
\hline $\mathrm{P}_{1}$ & 50 & 50 & 52 & 51 & 50 & 51 \\
\hline \multicolumn{7}{|l|}{ Top 5\% } \\
\hline $5 / 8 \mathrm{P}_{1} \mathrm{P}_{2}$ & 80 & 79 & 79 & 80 & 79 & 80 \\
\hline $3 / 4 \mathrm{P}_{1} \mathrm{P}_{2}$ & 87 & 87 & 83 & 90 & 87 & 87 \\
\hline $\mathrm{P}_{1}$ & 60 & 60 & 61 & 63 & 60 & 59 \\
\hline
\end{tabular}

${ }^{1}$ The fraction in front of the initials $\mathrm{P}_{1} \mathrm{P}_{2}$ represents the expected percentage of $\mathrm{P}_{1}$ alleles.

\section{DISCUSSION}

\section{Simulation}

Random regression models with linear splines are suitable to perform multiple-breed genetic evaluations. This model could be an efficient alternative when the use of MULT is limited. For example, with the use of RRMLS, there is no need to discard groups with few records, as is the case for the MULT. The possibility of obtaining BV solutions for animals that would be discarded in the MULT ensures greater accuracy for the estimates, as the number of animals evaluated is higher. Moreover, in cases where a large number of different breed groups are to be evaluated, the RRMLS performs the evaluation without increasing the model dimensionality. With the use of RRMLS it is possible to obtain solutions for all breed groups of a population, even for those that are intermediate to the adjusted knots. This implies that it is possible to obtain solutions for a greater number of breed groups than adjusted knots. In this way, the number of parameters is restricted to the number of adjusted knots and not to the number of breed groups present in the popula- tion, as happens in MULT. Besides that, the solutions of random regression coefficients directly represent the variances and the $\mathrm{BV}$ for the traits of interest at the adjusted knots (Misztal, 2006), which simplifies the evaluation.

The high correlations $(\geq 0.74)$ between simulated and estimated BV confirms the applicability of MULT and RRMLS in multiple-breed genetic evaluations (Table 4). Cardoso and Tempelman (2004) reported correlation between simulated and estimated BV through a multiple-breed model of 0.57 . The correlation values obtained in our study (Table 5) were similar or higher than those presented by the authors (Cardoso and Tempelman, 2004) and showed efficiency when MULT and RRMLS models were used for predicting BV of animals for selection. The higher correlation values observed in the present study may have occurred due to the higher number of simulated records and the heritability of the trait. In the present study, there were simulated records of 32,000 animals, whereas Cardoso and Tempelman (2004) simulated only 4.000 records. In addition, the progeny size for each sire could influence the correlation between the estimated and simulated genetic values, but not between the different breed groups.

Table 6. Deviance information criterion $\left(\times 10^{-3}\right)$ values of the random regression models for analysis of age at first calving (AFC), lactation length (LL), and 305-d milk yield (MY-305) at the first lactation of Holstein-Gyr multiple breed population

\begin{tabular}{llccc}
\hline Knots & Residual variances & AFC & LL & \multirow{2}{*}{ MY-305 } \\
\hline $0,0.5,0.875$ & Homogeneous & 53.22 & 36.79 & 122.24 \\
$0,0.5,0.875$ & Heterogeneous & 53.13 & 36.70 & 121.96 \\
$0,0.25,0.5,0.75,0.875$ & Homogeneous & 52.60 & 36.72 & 121.76 \\
$0,0.25,0.5,0.75,0.875$ & Heterogeneous & 53.17 & 37.16 & 122.28 \\
$0,0.25,0.375,0.5,0.75,0.875$ & Homogeneous & 51.38 & 36.23 & 122.14 \\
$0,0.25,0.375,0.5,0.75,0.875$ & Heterogeneous & 52.22 & 36.27 & 121.80 \\
\hline
\end{tabular}


Table 7. Posteriori means and lower and upper values of the highest posterior density intervals with $90 \%$ of samples (in brackets) of the correlations between the random regression coefficients used to adjust breeding values for age at first calving (AFC), lactation length (LL), and 305-d milk yield of the first lactation (MY-305) of Holstein (H)-Gyr (G) multiple breed population

\begin{tabular}{lccc}
\hline Group $^{1}$ & AFC & LL & MY-305 \\
\hline Gyr $-3 / 8 \mathrm{HG}$ & $0.09(-0.52 ; 0.69)$ & $0.07(-0.48 ; 0.61)$ & \\
Gyr $-1 / 4 \mathrm{HG}$ & $0.04(-0.56 ; 0.57)$ & $0.02(-0.61 ; 0.61)$ & $0.12(-0.73 ; 0.80)$ \\
Gyr $-1 / 2 \mathrm{HG}$ & $0.18(-0.86 ; 0.38)$ & $0.19(-0.43 ; 0.80)$ & $0.18(-0.52 ; 0.80)$ \\
$3 / 8 \mathrm{HG}-1 / 4 \mathrm{HG}$ & $-0.24(-0.30 ; 0.75)$ & $0.14(-0.26 ; 0.68)$ & \\
$3 / 8 \mathrm{HG}-1 / 2 \mathrm{HG}$ & $-0.13(-0.60 ; 0.37)$ & $0.11(-0.37 ; 0.65)$ & $0.36(-0.02 ; 0.68)$ \\
$1 / 4 \mathrm{HG}-1 / 2 \mathrm{HG}$ & $-0.17(-0.77 ; 0.30)$ & $0.39(0.00 ; 0.78)$ & \\
$1 / 4 \mathrm{HG}-5 / 8 \mathrm{HG}$ & $-0.02(-0.61 ; 0.53)$ & $0.35(-0.47 ; 0.54)$ & \\
$1 / 2 \mathrm{HG}-5 / 8 \mathrm{HG}$ & $0.10(-0.26 ; 0.46)$ & $0.20(-0.17 ; 0.56)$ & $0.07(-0.11 ; 0.26)$ \\
$1 / 2 \mathrm{HG}-3 / 4 \mathrm{HG}$ & $-0.18(-0.44 ; 0.07)$ & $0.11(-0.17 ; 0.41)$ & \\
$1 / 2 \mathrm{HG}-7 / 8 \mathrm{HG}$ & $0.06(-0.44 ; 0.44)$ & $0.42(-0.35 ; 0.47)$ & $0.36(-0.03 ; 0.69)$ \\
$5 / 8 \mathrm{HG}-3 / 4 \mathrm{HG}$ & $0.00(-0.27 ; 0.38)$ & $0.08(-0.12 ; 0.73)$ & \\
$5 / 8 \mathrm{HG}-7 / 8 \mathrm{HG}$ & $0.00(-0.39 ; 0.41)$ & $0.06(-0.31 ; 0.45)$ & $0.14(-0.20 ; 0.46)$ \\
$3 / 4 \mathrm{HG}-7 / 8 \mathrm{HG}$ & $0.13(-0.20 ; 0.47)$ & $0.06(-0.22 ; 0.44)$ & \\
\hline
\end{tabular}

${ }^{1}$ The fraction in front of the initials HG represents the expected percentage of Holstein alleles.

\section{Age at first calving}
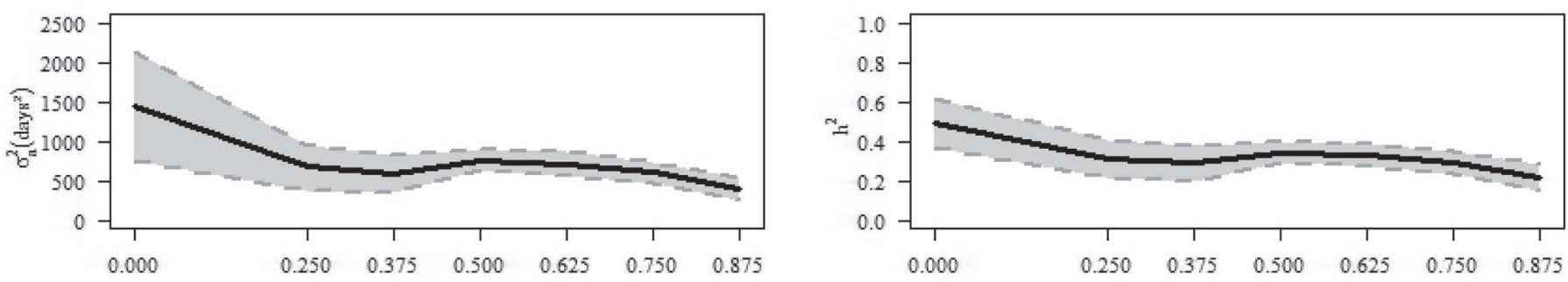

\section{Lactation length}
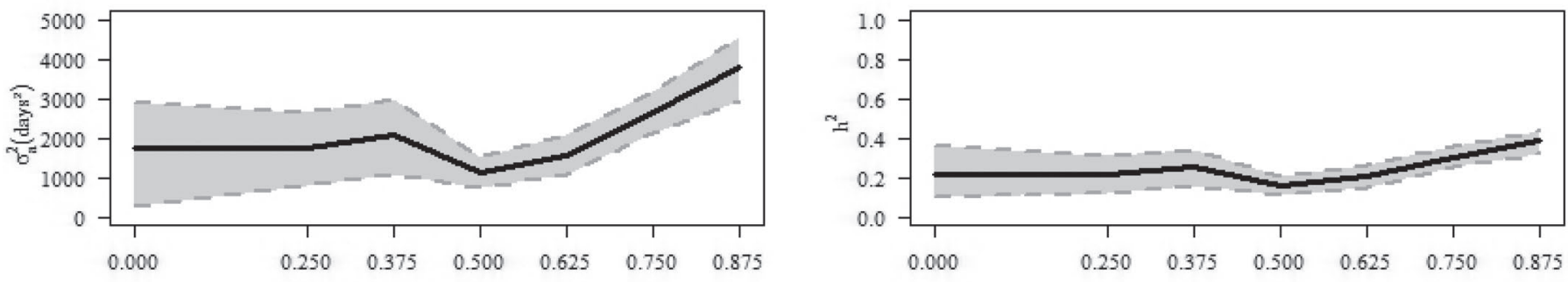

305-day milk yield

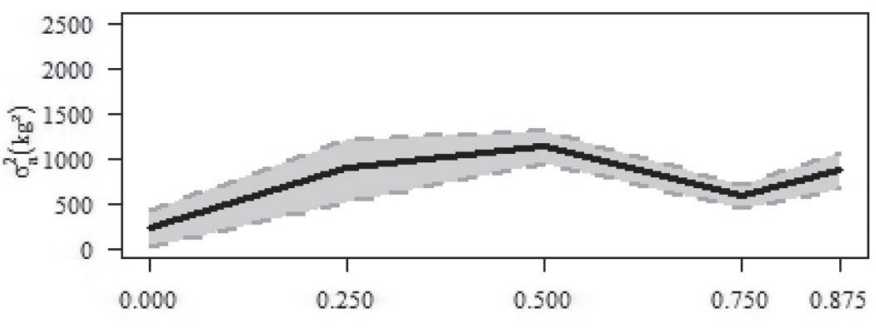

Holstein (\%)

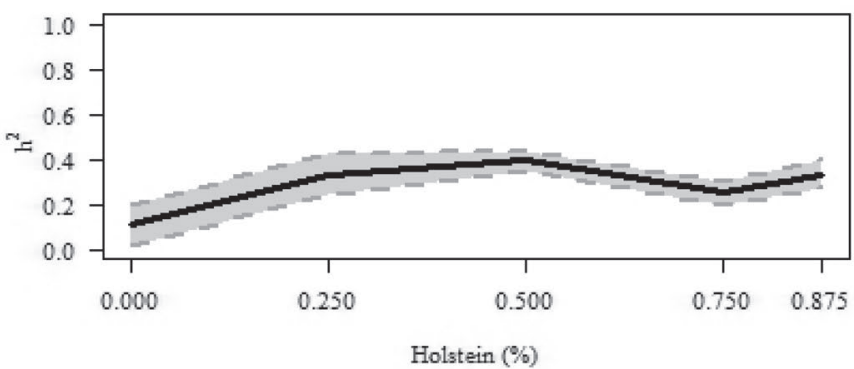

Holstein (\%)

Figure 2. Genetic variances $\left(\sigma_{a}^{2}\right.$; left) and $\mathrm{h}^{2}$ (right) for age at first calving $\left(\times 10^{-1}\right)$, lactation length, and 305-d milk yield of the first lactation $\left(\times 10^{-3}\right)$ of cows from a multiple breed population according to the breed group (fraction of Holstein). The horizontal axis marks represent the knots of the models considered. Posterior means (solid lines) and upper and lower limits (dashed lines) of the high-density intervals (shading) with $90 \%$ of the samples of the samples of genetic variances. 


\section{Field Data}

The same multiple-breed Gyr-Holstein data set with 9 distinct breed groups was used for models with 3 , 5 , and 7 knots (Table 3), suggesting that the benefit of using all records in the RRMLS analyses does not depend on the number of adjusted knots. To avoid estimation and convergence problems when MULT is used, in most cases it is necessary to exclude data from breed groups with few records (Bohmanova et al., 2005). In RRMLS, the knots just need to be adjusted in the most representative genetic groups, as in the present study, and (co)variances for the intermediate groups may be obtained by interpolation. This ensures that data from poorly representative breed groups are not excluded and contribute to increase accuracy of prediction for genetically related animals (VanRaden et al., 2007). Moreover, the model that best fitted MY-305 was the one with 5 knots (Table 6), suggesting that model adjustment also depends on the evaluated traits and not only on a higher number of adjusted knots. Thus, it is not necessary to adjust knots for all breed groups, because the model with higher parameterization will not always best fit to multiple breed data.

Feeding systems and specific management for each breed group may be used to improve productivity in multiple-breed cattle production. This can result in heterogeneity of residual variance (Toral et al., 2012). In fact, models with heterogeneous residual variances presented a better fit when compared with the ones with homogeneous residual variances for the genetic evaluation of postweaning weight gain of NelloreHereford crosses (Cardoso et al., 2005). However, these results differ from those obtained in the present study, most likely because in dairy cattle systems the management groups are formed by animals with different breed compositions considering their milk production levels and lactation stages. In this way, because each contemporary group included animals of different breed compositions, we were unlikely to observe differences in the residual variances due to the environmental variations to which the genetic groups were subjected.

Multiple-breed variance and heritability is specific to each breed group (Figure 2; Elzo et al., 2004; Heins et
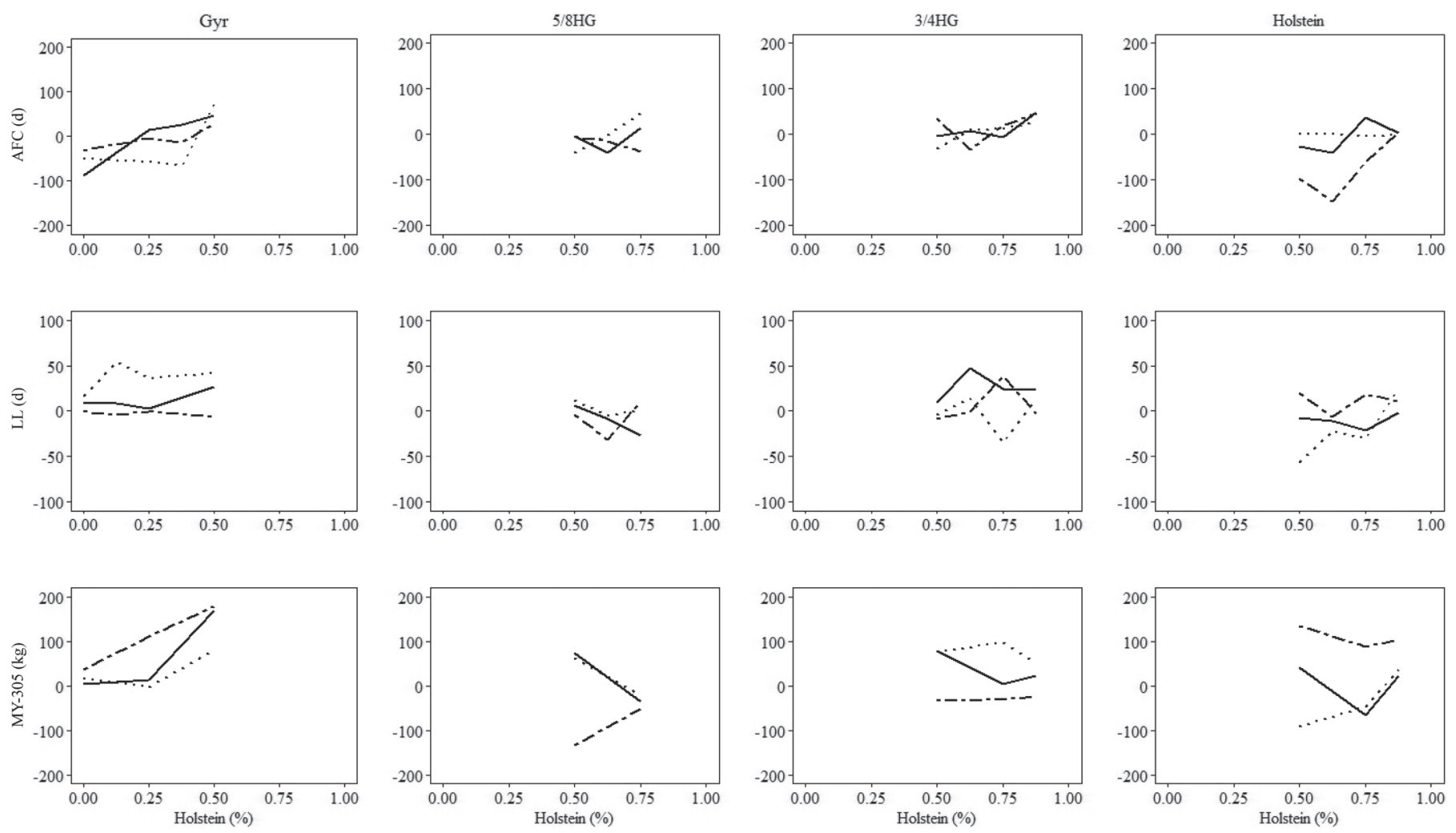

Figure 3. Breeding values for age at first calving (AFC), lactation length (LL), and 305-d milk yield (MY-305, $\times 10^{-1}$ ) for the 3 different sires (solid, dashed, and dotted lines) Gyr, 5/8 Holstein $+3 / 8$ Gyr $(5 / 8 \mathrm{HG}), 3 / 4$ Holstein $+1 / 4$ Gyr $(3 / 4 \mathrm{HG})$, and Holstein with highest numbers of daughters, evaluated according to the breed group of the daughters. 
al., 2011; VanRaden et al., 2011); therefore, RRMLS are suitable to estimate the genetic parameters of productive and reproductive traits in multiple-breed populations, once it provides distinct estimates of sire BV for each progeny breed group (Ribeiro et al., 2017). The heritability for AFC, LL, and MY-305 has shown moderate magnitude (Figure 2); thus, the selection process could modify the phenotypic means of these traits over the generations. However, when the same intensity of selection is considered, the response to selection for these traits may not be the same for the different breed groups.

The correlation among the random regression coefficients used to adjust the sires BV did not differ from zero (Table 7), as found by Vallée et al. (2013) and Ribeiro et al. (2017). Those authors demonstrated that the sire BV is related to the breed composition of their progeny and the BV obtained by purebred progeny records differs from that of crossbred progeny. This can be partially explained by specific combination ability (Arnold et al., 1992), in which the parents have a specific genetic composition and, when in combination with a particular breed, they will contribute to individual heterosis in the progeny to a greater or lesser extent than another parent of the same breed. Other factors that might have contributed to the differences in sire $\mathrm{BV}$, when estimated by different progeny breed groups, could be associated with the different heterozygosity levels of the breed groups, the existence of segregation variance among the different breeds (Lo et al., 1993), and the unbalanced distribution of crossbred progeny of each sire in the contemporary groups (Lukaszewicz et al., 2015).

In this way, by obtaining $\mathrm{BV}$ of sires according to the breed composition of their progeny, it is possible to improve the quality of genetic evaluation of animals belonging to multiple breed populations. In general, an interaction occurs between the sire BV and the progeny breed group from which that BV was estimated. Consideration of this interaction may increase the accuracy of the selection and direct matings, providing greater genetic progress. It is important to note that for LL we noted a Gyr sire that was always ranked first, regardless of the breed progeny group from which it was evaluated. The same was true for Gyr and Holstein sires evaluated for MY-305 (Figure 3, both sires represented by dot-dash line). When these sires, which present relatively constant BV, are selected, they would assure genetic progress regardless of the breed group of the mating cow due to the robustness of their BV with regards to the progeny breed group. Reranking of all 5/8HG and 3/4HG sires was observed for AFC, LL, and MY-305, probably as consequence of the greater segregation in the progeny of crossbred parents in relation to the segregation in the progeny of purebreds.

\section{CONCLUSIONS}

Random regression models with linear splines are suitable for obtaining genetic parameters in multiple breed populations. An interaction occurred between the breeding value of the sires and their progeny group with different breed composition. Therefore, the parameters and breeding values for age at first calving, first lactation length, and 305-d milk yield traits from a multiplebreed population depend on breed composition of the progeny from which the evaluations are obtained.

\section{REFERENCES}

Arnold, J. W., J. K. Bertrand, and L. L. Benyshek. 1992. Animal model for genetic evaluation of multibreed data. J. Anim. Sci. 70:3322-3332. https://doi.org/10.2527/1992.70113322x.

Bohmanova, J., I. Misztal, and J. K. Bertrand. 2005. Studies on multiple trait and random regression models for genetic evaluation of beef cattle for growth. J. Anim. Sci. 83:62-67. https://doi.org/10 $.2527 / 2005.83162 x$

Cardoso, F. F., G. J. M. Rosa, and R. J. Tempelman. 2005. Multiple-breed genetic inference using heavy-tailed structural models for heterogeneous residual variance. J. Anim. Sci. 83:1766-1779. https://doi.org/10.2527/2005.8381766x.

Cardoso, F. F., and R. J. Tempelman. 2004. Hierarchical Bayes multiple-breed inference with an application to genetic evaluation of a Nelore-Hereford population. J. Anim. Sci. 82:1589-1601. https:// doi.org/10.2527/2004.8261589x.

Elzo, M. A., A. Jara, and N. Barria. 2004. Genetic parameters and trends in the Chilean multibreed dairy cattle population. J. Dairy Sci. 87:1506-1518. https://doi.org/10.3168/jds.S0022 -0302(04)73302-0.

Geweke, J. 1992. Evaluating the accuracy of sampling-based approaches to the calculation of posterior moments (with discussion). Pages 164-193 in Bayesian Statistics. J. O. Berger, J. M. Bernardo, A. P. Dawid, and A. F. M. Smith, ed. Oxford University Press, Oxford, UK.

Heins, B. J., L. B. Hansen, A. R. Hazel, A. J. Seykora, D. G. Johnson, and J. G. Linn. 2011. Short communication: Jersey $\times$ Holstein crossbreds compared with pure Holsteins for production mastitis and body measurements during the first 3 lactations. J. Dairy Sci. 94:501-506. https://doi.org/10.3168/jds.2010-3232.

Lo, L. L., R. L. Fernando, and M. Grossman. 1993. Covariance between relatives in multibreed populations: Additive model. Theor. Appl. Genet. 87:423-430. https://doi.org/10.1007/BF00215087.

Lukaszewicz, M., R. Davis, J. K. Bertrand, I. Misztal, and S. Tsuruta. 2015. Correlations between purebred and crossbred body weight traits in Limousin and Limousin-Angus populations. J. Anim. Sci. 93:1490-1493. https://doi.org/10.2527/jas.2014-8285.

Misztal, I. 2006. Properties of random regression models using linear splines. J. Anim. Breed. Genet. 123:74-80. https://doi.org/10 $.1111 /$ j.1439-0388.2006.00582.x.

Misztal, I., S. Tsuruta, D. Lourenço, I. Aguilar, A. Legara, and Z. Vitezica. 2014. Manual for BLUPF90 Family of Programs. University of Georgia, Athens.

Quaas, R. L. 1988. Additive genetic model with groups and relationships. J. Dairy Sci. 71:1338-1345. https://doi.org/10.3168/jds .S0022-0302(88)79691-5. 
R Core Team. 2015. R: A language and environment for statistical computing. R Foundation for Statistical Computing, Vienna, Austria. Accessed Mar. 1, 2015. http://www.R-project.org/.

Raftery, A. L., and S. Lewis. 1992. One long run with diagnostics: implementation strategies for Markov chain Monte Carlo. Stat. Sci. 7:493-497. https://doi.org/10.1214/ss/1177011143.

Ribeiro, V. M. P. R., F. A. Merlo, G. C. G. Gouveia, L. K. Winkelstroter, L. R. A. Abreu, M. V. G. B. Silva, J. C. C. Panetto, L. C. Paiva, M. A. R. Cembranelli, and F. L. B. Toral. 2017. Genetic analysis of productive and reproductive traits in multiple-breed dairy cattle populations. Pesqui. Agropecu. Bras. 52:1109-1117. https://doi.org/10.1590/S0100-204X2017001100017.

Smith, B. J. 2005. Bayesian output analysis program (boa) version 1.1 user's manual. 43p. Accessed Mar. 1, 2015. http://www.public -health.uiowa.edu/boa/boa.pdf.

Sorensen, D., and D. Gianola. 2002. Likelihood Bayesian and MCMC Methods in Quantitative Genetics. Springer-Verlag, New York, NY. https://doi.org/10.1007/b98952.

Spiegelhalter, D. J., N. G. Best, B. P. A. Carlin, and V. D. Linde. 2002. Bayesian measures of model complexity and fit. J. R. Stat.
Soc. B Stat. Methodol. 64:583-639. https://doi.org/10.1111/1467 $-9868.00353$.

Toral, F. L. B., R. A. A. Torres Júnior, P. S. Lopes, F. F. Cardoso, and L. O. C. Silva. 2012. Heteroskedasticity for weaning weight of Charolais-Zebu crossbred calves. Rev. Bras. Zootec. 41:1163-1172. https://doi.org/10.1590/S1516-35982012000500013.

Vallée, A., J. A. M. Van Arendonk, and H. Bovenhuis. 2013. Genetic parameters for calving and conformation traits in Charolais $x$ Montbéliard and Charolais $\times$ Holstein crossbred calves. J. Anim. Sci. 91:5582-5588. https://doi.org/10.2527/jas.2013-6490.

VanRaden, P. M., K. M. Olson, G. R. Wiggans, J. B. Cole, and M. E. Tooker. 2011. Genomic inbreeding and relationships among Holsteins, Jerseys, and Brown Swiss. J. Dairy Sci. 94:5673-5682. https://doi.org/10.3168/jds.2011-4500.

VanRaden, P. M., M. E. Tooker, J. B. Cole, G. R. Wiggans, and J. H. Megonigal Jr. 2007. Genetic evaluations for mixed-breed populations. J. Dairy Sci. 90:2434-2441. https://doi.org/10.3168/jds .2006-704. 